\title{
Perbandingan Laringoskopi Indirek Kaca Laring dengan Laringoskopi Indirek Video Smartphone dalam Menilai Visualisasi Laring dan Kenyamanan Pasien
}

\author{
Paulus Sulistiono, M. Andy Prihartono, Dedi Fitri Yadi \\ Departemen Anestesiologi dan Terapi Intensif \\ Fakultas Kedokteran Universitas Padjadjaran/RSUP Dr. Hasan Sadikin Bandung
}

\begin{abstract}
Abstrak
Salah satu pemeriksaan preoperatif yang dapat digunakan sebagai prediktor kesulitan intubasi adalah laringoskopi indirek. Penelitian ini bertujuan menilai visualisasi laring dan kenyamanan pasien antara laringoskopi indirek kaca laring dan laringoskopi indirek video smartphone. Penelitian menggunakan metode prospective randomized parallel trial, dilakukan di Rumah Sakit Dr. Hasan Sadikin (RSHS) Bandung pada bulan November-Desember 2017. Pasien dibagi menjadi kelompok laringoskopi indirek kaca laring (kelompok LIKL, $\mathrm{n}=22$ ) dan kelompok laringoskopi indirek video smartphone (kelompok LIVS, $\mathrm{n}=22$ ). Uji statistik menggunakan Uji Mann-Whitney. Hasil penelitian mengungkapkan visualisasi laring lebih jelas pada kelompok LIVS $(1,73 \mathrm{SD} \pm 0,77)$ dibanding dengan kelompok LIKL $(2,50 \mathrm{SD} \pm 0,86)$ dengan perbedaan signifikan $(\mathrm{p}<0,05)$. Kenyamanan yang lebih baik pada kelompok LIVS (skala di atas 5) dibanding dengan kelompok LIKL (skala di atas 5) dengan perbedaan signifikan $(p<0,05)$. Simpulan penelitian ini adalah visualisasi laring dan kenyamanan pasien pada laringoskopi indirek dengan video smartphone lebih baik bila dibanding dengan laringoskopi indirek kaca laring.
\end{abstract}

Kata kunci: Kaca laring, kesulitan intubasi, laringoskopi indirek, video smartphone

\section{Comparison between Indirect Laryngoscopy Laryngeal Mirror and Indirect Laryngoscopy Smartphone Video in Evaluating Laryngeal Visualization and Patient Comfort}

\begin{abstract}
Indirect laryngoscopy is an examination modality which can be performed during pre-operative phase as a predictor of difficult intubation. The purpose of this study was to compare indirect laryngoscopy using laryngeal mirror and indirect laryngoscopy using smartphone video in evaluating laryngeal visualization and providing convenience to patients during the examination procedure. This prospective randomized parallel trial was conducted at Dr. Hasan Sadikin General Hospital Bandung from November to December 2017. Patients were assigned to two study groups: those who underwent indirect laryngoscopy using laryngeal mirror (LIKL group, $\mathrm{n}=22$ ) and those who underwent indirect laryngoscopy using smartphone video (LIVS group, $\mathrm{n}=22$ ). Mann-Whitney test was utilized as the statistical test method. Result of this study showed that laryngeal visualization was significantly superior in LIVS group compared to LIKL group (1.73 $\mathrm{SD} \pm 0.77$ vs $2.50 \mathrm{SD} \pm 0.86$, respectively, $\mathrm{p}$ value $<0.05$ ). Patient comfort was significantly superior in LIVS group compared to LIKL group (comfort score above 5 vs comfort score above 5 , respectively, p value $<0.05$ ). Therefore, it is concluded that laryngeal visualization using indirect langryngoscopy with smartphone video is more comfortable than the one that uses direct laryngoscopy with laryngeal mirror.
\end{abstract}

Key words: Difficult intubation, indirect laryngoscopy, laryngeal mirror, smartphone video

Korespondensi: Paulus Sulistiono, dr., SpAn, Departemen Anestesiologi dan Terapi Intensif Fakultas Kedokteran Universitas Padjadjaran/Rumah Sakit Dr. Hasan Sadikin Bandung, Jl. Pasteur No.38 Bandung 40161,Email paulusmukri@ gmail.com 


\section{Pendahuluan}

Salah satu tanggung jawab utama ahli anestesi adalah mengelola jalan napas, memelihara, dan menjaga patensi jalan napas sejak awal hingga akhir pembedahan untuk memastikan pasien mendapatkan oksigenasi yang adekuat selama pembedahan. ${ }^{1}$ Prosedur yang menjadi standar dalam mempertahankan patensi jalan napas yang memadai adalah intubasi endotrakeal. Penyebab utama morbiditas dan mortalitas pada pasien yang menjalani prosedur anestesi adalah kegagalan intubasi endotrakeal disertai ketidakmampuan mempertahankan patensi jalan napas dan oksigenasi yang adekuat.

Jalan napas yang sulit dapat menyebabkan kegagalan saat prosedur intubasi endotrakeal dilakukan. Angka kejadian kesulitan intubasi pada pasien yang menjalani pembedahan dengan anestesi umum bervariasi antara 1,5\% sampai $13 \% .^{3}$ Kegagalan intubasi berpotensi memicu timbulnya masalah yang serius seperti hipoventilasi, hipoksemia, kerusakan sel-sel, otak dan kematian. Oleh karena itu, pemeriksaan preoperatif untuk mendeteksi kesulitan menjaga patensi jalan napas sangat penting dilakukan., ${ }^{2,3}$

Beberapa modalitas yang digunakan untuk memprediksi kesulitan saat visualisasi laring, yaitu uji modifikasi mallampati (UMM), skor risiko Wilson, pembukaan mulut, subluksasi mandibula, mobilitas servikal,jarak tiromental, jarak sternomental, dan lingkar leher., ${ }^{3,4}$

Pemeriksaan yang sering dilakukan untuk menilai jalan napas secara kualitatif adalah UMM oleh Samsoon dan Young. Pemeriksaan ini dilaksanakan untuk mengukur volume lidah dan faring dengan membandingkan ukuran lidah dengan ukuran faring. Pemeriksaan ini dilakukan dalam posisi pasien duduk tegak dengan kepala pada posisi netral, kemudian pasien diminta untuk membuka mulut dan menjulurkan lidah semaksimal-maksimalnya. Pemeriksaan ini sangat bergantung pada posisi dan kemampuan pasien dalam membuka mulut serta menjulurkan lidah sehingga sering kali terjadi kesalahan klasifikasi dalam penilaian pasien dengan penurunan kesadaran atau pasien yang tidak mampu membuka mulut maupun menjulurkan lidah secara maksimal. ${ }^{1,2,5,6}$

Modalitas lain yang dapat digunakan sebagai prediktor kesulitan intubasi, yaitu laringoskopi indirek. Laringoskopi indirek merupakan pemeriksaan yang sangat penting dalam menilai visualisasi dan patologi laring. Beberapa penelitian menunjukkan bahwa indirek laringoskopi lebih superior dibanding dengan penilaian Mallampati dan Wilson risk sum. Teknik pemeriksaan ini menggunakan kaca laring yang diposisikan pada posterior faring dengan tujuan memperjelas visualisasi laring dengan menggunakan cahaya yang direfleksikan oleh kaca tersebut. Pemeriksaan dilakukan dalam posisi pasien duduk, pinggul menempel pada kursi atau tempat tidur, tubuh diarahkan sedikit ke arah depan, mengangkat dada dan dagu, melakukan ekstensi leher, dan menjulurkan serta melemaskan lidahnya. Teknik pemeriksaan ini terlihat sederhana, tetapi memerlukan keterampilan khusus dalam aplikasinya. Laringoskopi indirek memiliki banyak keuntungan dan beberapa kerugian. Salah satu kerugian pemeriksaan ini adalah rumitnya komponen peralatan penunjang yang dibutuhkan untuk melakukan pemeriksaan dan harus dibawa pada saat pemeriksaan preoperatif oleh dokter anestesi. Terdapat beberapa alternatif yang dapat digunakan untuk mengatasi hal ini, salah satunya adalah pemeriksaan laringoskopi indirek dengan menggunakan video smartphone. . $^{1-3,6-8}$

Terdapat penelitian yang membandingkan pemeriksaan laringoskopi indirek memakai video endoskopi laring dengan pemeriksaan laringoskopi indirek menggunakan kaca laring. Penelitian tersebut menyatakan bahwa video endoskopi laring lebih superior dalam menilai visualisasi laring dan kenyamanan pasien dengan alat endoskopi yang terhubung dengan monitor yang sulit untuk dimobilisasi. 7

Pada penelitian ini video endoskopi laring dimodifikasi menggunakan video smartphone. Teknik pemeriksaan hampir sama dengan laringoskopi indirek menggunakan kaca laring. Perbedaan terdapat pada modalitas yang digunakan, bila pada penelitian sebelumnya 
digunakan endoskopi yang terhubung dengan monitor yang pada pelaksanaannya sulit untuk dibawa, besar, dan mahal maka pada penelitian ini digunakan kamera endoskopi yang terhubung dengan smartphone sehingga lebih mudah dibawa, murah, serta mudah digunakan. Pemeriksaan ini dilakukan untuk menilai visualisasi laring yang akan dinilai menggunakan skor Cormack-Lehane, dan penilaian kenyamanan pasien yang dinilai menggunakan skala $1-10$, dengan skala 1 pasien merasa nyaman tanpa ada refleks muntah dan skala 10 pasien merasa sangat tidak nyaman dengan refleks muntah hebat.

Penelitian ini bertujuan membandingkan laringoskopi indirek kaca laring dengan laringoskopi indirek video smartphone dalam menilai visualisasi laring dan kenyamanan pasien saat dilakukan laringoskopi indirek.

\section{Subjek dan Metode}

Penelitian ini menggunakan metode analitik eksperimental prospektif randomized parallel trial. Penelitian dilakukan di ruang perawatan RSUP Dr. Hasan Sadikin (RSHS) Bandung pada bulan November hingga Desember 2017 dan telah mendapatkan persetujuan dari Komite Etik Penelitian Kesehatan Fakultas Kedokteran Universitas Padjadjaran/RSHS Bandung. Subjek penelitian ini adalah pasien yang menjalani pembedahan dengan anestesi umum menggunakan pipa endotrakeal.

Kriteria inklusi subjek penelitian ini adalah usia 18-65 tahun, pasien menjalani pembedahan dengan anestesi umum dan pemasangan pipa endotrakeal, kooperatif, dan Mallampati I-II. Kriteria eksklusi, yaitu indeks massa tubuh lebih dari 24, trauma pada daerah wajah, buka mulut kurang dari 3 jari pasien, dan kelainan anatomi seperti lidah besar, leher pendek, micrognathia, dan prognatishme. Penentuan besar sampel dilakukan berdasar atas perhitungan statistik dengan rumus uji hipotesis beda rata-rata, dengan taraf nyata $5 \%$ dan kekuatan uji $80 \%$ dan diperoleh besar sampel tiap-tiap kelompok sebanyak 22 sampel. Teknik pengambilan sampel adalah consecutive sampling dengan alokasi subjek ke dalam kelompok menggunakan metode randomisasi blok.

Subjek penelitian terdiri atas 44 pasien yang terbagi menjadi 2 kelompok. Kelompok I menjalani pemeriksaan laringoskopi indirek kaca laring sedangkan kelompok II menjalani pemeriksaan laringoskopi indirek video smartphone. Pada kedua kelompok dilakukan penilaian visualisasi laring dan kenyamanan saat dilakukan laringoskopi indirek.

Peralatan laringoskopi indirek kaca laring terdiri atas kaca laring 45 derajat, kassa, lidokain spray, dan lampu kepala. Peralatan laringoskopi indirek video smartphone terdiri atas USB android endoskopi $7 \mathrm{~mm}$ yang dihubungkan dengan kaca 45 derajat dan tersambung dengan smartphone android yang mempunyai aplikasi Scopecam atau CameraFi, kemudian kassa dan spray lidokain seperti yang dapat dilihat pada Gambar 1.

Laringoskopi indirek menggunakan kaca laring dilakukan dalam posisi pasien duduk, pinggul menempel pada kursi atau tempat tidur, tubuh diarahkan ke depan, dada dan dagu diangkat, leher ekstensi, dan menjulurkan serta melemaskan lidah dengan pandangan lurus ke depan, kemudian pemeriksa memberikan spray lidokain pada dinding faring dan dasar lidah. Pemeriksa menggunakan kasa ukuran $4 \mathrm{x} 4 \mathrm{~cm}$ untuk memegang lidah pasien dengan tangan kiri, lalu memasukan kaca laring menggunakan tangan kanan ke dalam mulut pasien. Kaca laring yang digunakan terlebih dulu dihangatkan untuk mengurangi embun pada saat dilakukan pemeriksaan. Posisi pasien dan pemeriksa pada kelompok laringoskopi indirek video smartphone, sama dengan kelompok laringoskopi indirek kaca laring. Pada kelompok laringoskopi indirek video smartphone visualisasi laring dilihat dengan mempergunakan kamera endoskopi yang dihubungkan ke smartphone kemudian tampilan visualisasi laring akan terlihat pada smartphone pemeriksa.

Visualisasi laring pada kedua kelompok dinilai menggunakan skor klasifikasi CormackLehane. Klasifikasi ini terbagi menjadi 4 kelas, semakin tinggi kelas maka visualisasi laring semakin tidak jelas. Kelas 1 tampak glotis 
a.
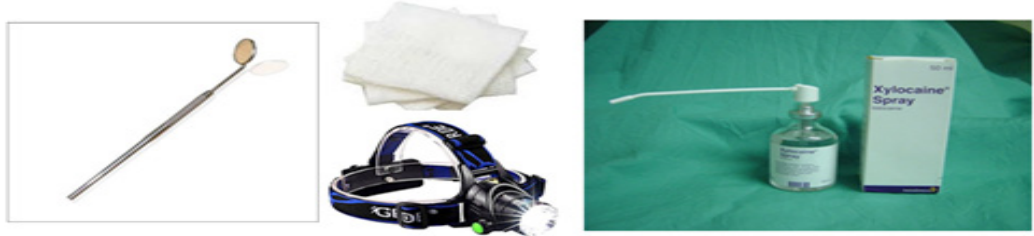

b.
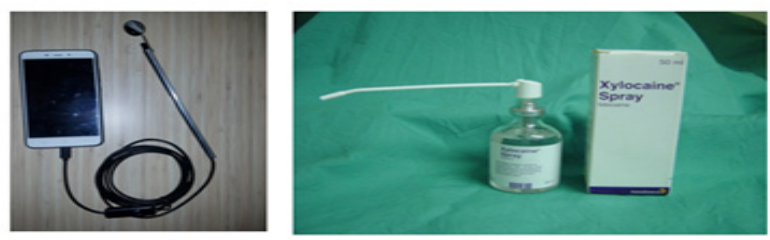

Gambar 1 Laringoskopi Indirek

Keterangan: a. Laringoskopi indirek kaca laring, b. Laringoskopi indirek video smartphone Sumber: dokumentasi pribadi

secara menyeluruh, kelas 2 hanya tampak komisura posterior, kelas 3 hanya tampak ujung epiglotis, dan kelas 4 tidak tampak struktur glotis sama sekali.

Hasil visualisasi laring kedua kelompok akan dikonfirmasi menggunakan laringoskopi direk. Konfirmasi direk laringoskopi dilakukan pada saat pasien dalam kondisi teranestesi dan menggunakan laringoskopi C-MAC $®$ sehingga hasil visualisasi dapat didokumentasikan. Hasil konfirmasi ini akan menjadi indikator kesesuaian visualisasi laring pada kedua kelompok penelitian.

Kenyamanan pasien pada saat laringoskopi indirek dinilai dengan skala kenyamanan. Skala kenyamanan terbagi menjadi 10 skala dengan skala 1 menyatakan pasien sama sekali tidak merasakan ketidaknyamanan dan sama sekali tidak merasakan mual ataupun muntah, sedangkan skala 10 menunjukkan sensasi yang sangat tidak nyaman dengan perasaan mual muntah yang hebat.

Uji statistik penelitian ini menggunakan Uji Mann-Whitney. Data hasil penelitian dicatat dan diolah menggunakan program statistical product and service solution (SPSS) versi 24.0 for windows.

\section{Hasil}

Gambaran karakeristik subjek penelitian berdasar atas jenis kelamin, indeks massa tubuh, dan Mallampati antara kedua kelompok tidak ada perbedaan bermakna ( $p>0,05$; Tabel 1).

Visualisasi laring pada kelompok LIVS lebih jelas dibanding atas dengan kelompok LIKL dengan nilai $p$ yang dihasilkan dari Uji Mann Whitney sebesar $0,004(p<0,05)$ yang menunjukkan bahwa hasil skor visualisasi pada kedua kelompok dinyatakan memiliki perbedaan secara sangat bermakna (Gambar 2). Penilaian visualisasi ditunjang dengan hasil konfirmasi direk laringoskopi pada tiap-tiap kelompok seperti yang terlihat pada Tabel 2 . Hasil konfirmasi laringoskopi direk kelompok II menghasilkan angka kesesuaian yang lebih baik (20 dari 22 sampel) dibanding dengan angka kesesuaian pada kelompok laringoskopi indirek kaca laring (10 dari 22 sampel).

Berdasar atas hasil Uji Mann-Whitney, kenyamanan pasien pada kelompok II lebih baik bila dibandingkan kelompok I dengan perbedaan bermakna $(\mathrm{p}<0,05$; Gambar 3$)$.

\section{Pembahasan}

Karakteristik umum subjek penelitian pada setiap kelompok perlakuan (Tabel 1), menunjukkan jenis kelamin, indeks massa tubuh, dan Mallampati pada kedua kelompok tidak ada perbedaan bermakna sehingga pasien secara statistik homogen dan layak dibandingkan. 
Tabel 1 Karakteristik Subjek Penelitian

\begin{tabular}{lccc}
\hline \multirow{2}{*}{ Karakteristik Pasien } & \multicolumn{2}{c}{ Kelompok } & \multirow{2}{*}{ Nilai p } \\
\cline { 2 - 3 } & LIVS (n=22) & LIKL (n=22) & \multirow{2}{*}{$1,000^{\mathrm{a}}$} \\
\hline Jenis kelamin & 6 & 7 & \\
$\quad$ Laki-laki & 16 & 15 & $0,204^{\mathrm{b}}$ \\
$\quad$ Perempuan & & & \\
Indeks massa tubuh (kg/m $\left.{ }^{2}\right)$ & $21,14(1,32)$ & $21,69(1,48)$ & $1,000^{\mathrm{a}}$ \\
$\quad$ Rerata (SD) & $18,07-23,34(5,27)$ & $18,47-23,81(5,34)$ & \\
$\quad$ Min.-Maks. (range) & 15 & 16 & \\
Mallampati & 7 & 6 & \\
1 & & & \\
2 & &
\end{tabular}

Keterangan: nilai p dihitung berdasarkan uji : a) chi-square dengan koreksi kontinuitas (tabel 2x2, n > 40), b) uji-t independen, perbedaan *) bermakna, jika $\mathrm{p}<5 \%,{ }^{* *}$ ) sangat bermakna, jika $\mathrm{p}<1 \%$

Penilaian Mallampati dapat digunakan sebagai estimasi ukuran lidah dibandingkan dengan rongga mulut dan dapat juga dipakai sebagai parameter sulit atau tidak memposisikan lidah pada saat intubasi. Sebagai tambahan, penilaian Mallampati juga dapat digunakan untuk menilai apakah mulut dapat dibuka secara maksimal pada saat intubasi. ${ }^{9}$ Pada penelitian ini didapatkan penilaian Mallampati I dan II pada kelompok laringoskopi indirek video smartphone dan kelompok laringoskopi indirek kaca laring yang tidak berbeda bermakna antara kedua kelompok $(\mathrm{p}>0,05)$.

Indeks massa tubuh berpengaruh terhadap struktur anatomis wajah. Pasien obesitas memiliki jumlah jaringan lemak yang besar yang dapat digambarkan dari rasio lingkar leher (NC) dan jarak tiromental (TM), hal ini yang memberikan pengaruh terhadapkesulitan intubasi. Insiden kesulitan intubasi pada pasien obesitas dengan indeks massa tubuh di atas 30 telah dilaporkan pada beberapa kasus. ${ }^{1}$ Pada penelitian ini, indeks massa tubuh rata-rata pada kelompok laringoskopi indirek video smartphone sebesar 21,14 dan 21,69

Tabel 2 Kesesuaian Laringoskopi Indirek dan Laringoskopi Direk berdasar atas Hasil Visualisasi Laring

\begin{tabular}{|c|c|c|c|}
\hline $\begin{array}{l}\text { Klasifikasi Cormack Lehane } \\
\text { (Laringoskopi Indirek) }\end{array}$ & $\begin{array}{l}\text { Konfirmasi Cormack Lehane } \\
\text { dengan Laringoskopi Direk }\end{array}$ & $\begin{array}{c}\text { LIVS } \\
(\mathrm{n}=22)\end{array}$ & $\begin{array}{c}\text { LIKL } \\
(n=22)\end{array}$ \\
\hline I & I & 10 & 3 \\
\hline \multirow[t]{2}{*}{ II } & I & 1 & 3 \\
\hline & II & 7 & 4 \\
\hline \multirow[t]{3}{*}{ III } & I & 0 & 6 \\
\hline & II & 1 & 1 \\
\hline & III & 3 & 3 \\
\hline IV & III & & 2 \\
\hline \multicolumn{2}{|c|}{ Tingkat kesesuaian } & 20 & 10 \\
\hline
\end{tabular}

Keterangan: LIVS (laringoskopi indirek video smartphone), LIKL (laringoskopi indirek kaca laring) 


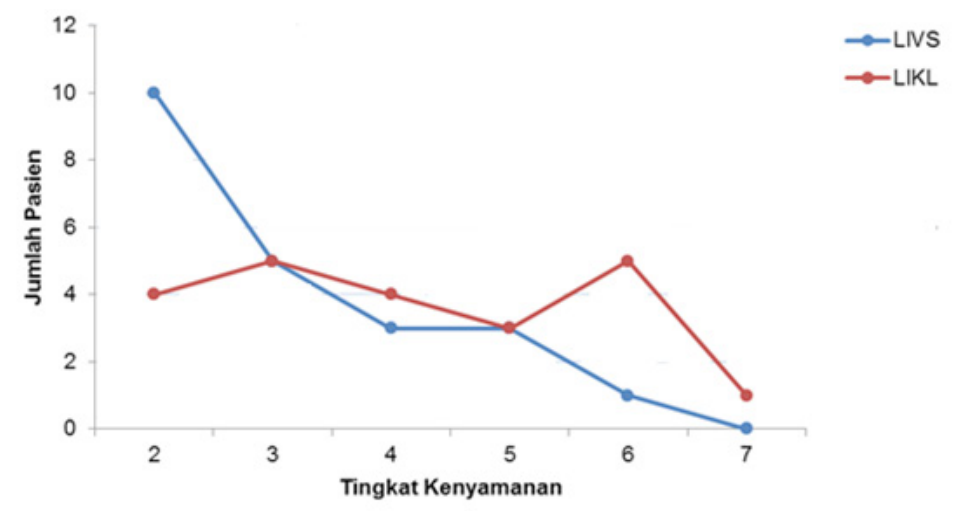

Gambar 2 Perbandingan Kenyamanan Pasien pada Kedua Kelompok

Ket.: LIVS (laringoskopi indirek video smartphone), LIKL (laringoskopi indirek kaca laring)

pada kelompok laringoskopi indirek kaca laring dengan tidak ada perbedaan bermakna pada kedua kelompok ( $\mathrm{p}>0,05)$.

Pada penelitian ini diketahui bahwa skor klasifikasi Cormack lehane pada laringoskopi indirek video smartphone didominasi oleh skor klasifikasi I sebanyak 10 orang dari 22 orang, sementara pada laringoskopi indirek kaca laring didominasi oleh skor klasifikasi III sebanyak 10 orang dari 22 orang.

Penelitian ini menunjukkan bahwa dengan subjek penelitian yang dianggap homogen menghasilkan visualisasi laring yang lebih jelas pada laringoskopi indirek dengan video smartphone dibanding dengan laringoskopi indirek kaca laring. Hal ini dibuktikan dengan hasil pada kelompok laringoskopi indirek video smartphone yang didominasi oleh skor klasifikasi I yang menunjukkan tampak glotis secara menyeluruh dibanding dengan kelompok laringoskopi indirek kaca laring yang didominasi oleh skor klasifikasi III dengan hanya tampak ujung epiglotis.

Hasil tersebut sesuai dengan penelitian yang menilai perbandingan laringoskopi indirek menggunakan video rigid laryngeal endoscopy (VRLE) dengan laringoskopi indirek menggunakan kaca laring (LME). Pada penelitian terhadap 43 pasien yang ditentukan secara acak tersebut, didapatkan bahwa pemeriksaan laringoskopi indirek menggunakan video rigid laryngeal endoscopy lebih baik dibandingkan dengan pemeriksaan laringoskopi indirek menggunakan kaca laring.
Laringoskopi indirek menggunakan video rigid laryngeal endoscopy lebih superior bila dibanding dengan pemeriksaan laringoskopi indirek menggunakan kaca laring dengan visualisasi epiglotis, aritenoid, dan posterior dari bagian tengah pita suara tercapai sebanyak 62,8\% dibanding dengan LME hanya sebanyak $37,2 \%{ }^{7}$

Hasil penelitian ini juga ditunjang dengan data konfirmasi direk laringoskopi. Dari kedua kelompok dilakukan konfirmasi dengan mengunakan direk laringoskopi, didapatkan hasil kesesuaian, yaitu sebesar 90,9\% dengan ketentuan hasil yang sesuai sebanyak 20 dari total 22 sampel, sementara kesesuaian pada kelompok laringoskopi indirek kaca laring dengan ketentuan hasil yang sesuai sebanyak 10 dari total 22 sampel. Dari hasil kesesuaian antara laringoskopi indirek dan laringoskopi direk didapatkan hasil kesesuaian yang lebih tinggi pada laringoskopi indirek dengan video smartphone.

Visualisasi laring yang lebih baik dihasilkan kelompok larigoskopi indirek video smartphone dipengaruhi oleh sudut yang dihasilkan kamera dengan kaca laring. Pada laringoskopi indirek kaca laring diperlukan kesejajaran mata pemeriksa, penerangan pada lampu kepala, dan kaca laring untuk mendapatkan visualisasi laring yang optimal, sedangkan pada laringoskopi indirek video smartphone tidak diperlukan kesejajaran ketiga hal tersebut karena kamera video smartphone juga dilengkapi dengan lampu 
penerangan dan visualisasi laring yang diproyeksikan oleh kamera muncul pada android smartphone pemeriksa. Kamera itu berfungsi sebagai mata pemeriksa sehingga secara tidak langsung mata pemeriksa dapat melihat laring tanpa terganggu lidah yang biasanya menjadi penghalang visualisasi pada laringoskopi indirek kaca laring. Beberapa faktor tersebut yang membuat visualisasi laring yang dihasilkan oleh kelompok laringoskopi indirek video smartphone lebih jelas dibanding dengan kelompok laringoskopi indirek kaca laring.

Pada penelitian ini, diketahui kelompok laringoskopi indirek video smartphone didominasi oleh skala kenyamanan sebanyak 10 dari 22 pasien, sementara pada kelompok laringoskopi indirek kaca laring didominasi oleh skala kenyamanan 3 dan 6 masingmasing sebanyak 5 dari 22 pasien. Penggunaan laringoskopi indirek dengan video smartphone memberikan tingkat kenyamanan yang lebih baik dibanding dengan laringoskopi indirek dengan kaca laring.

Hasil penelitian menunjukkan hanya 1 dari 22 pasien yang merasakan nilai kenyamanan di atas 5 pada pemeriksaan laringoskopi indirek dengan video smartphone, sedangkan pemeriksaan laringoskopi indirek dengan kaca laring menunjukkan 6 dari 22 pasien merasakan nilai kenyamanan di atas 5 .

Hasil tersebutsesuai dengan penelitian yang menilai perbandingan laringoskopi indirek menggunakan video rigid laryngeal endoscopy (VRLE) dengan laringoskopi indirek kaca laring (LME). Pada penelitian dengan 43 pasien tersebut, didapatkan hasil bahwa pemeriksaan laringoskopi indirek menggunakan kaca laring lebih menyebabkan ketidaknyamanan pasien dibanding dengan pemeriksaan laringoskopi indirek menggunakan video rigid laryngeal endoscopy. Hasil penilaian yang menggunakan VRLE didapatkan hanya 6 dari 43 pasien merasakan skor ketidaknyamanan di atas 5, dibanding dengan menggunakan LME dengan 18 pasien dari 43 pasien merasakan skor ketidaknyamanan di atas $5 .^{7}$

Ketidaknyamanan terhadap pemeriksaan laringoskopi indirek menggunakan kaca laring disebabkan oleh manipulasi yang berlebih pada saat memasukkan kaca laring ke dalam mulut pasien. Hal ini yang memberikan rangsangan semakin besar kepada pasien. Sebaliknya, pada pemeriksaan laringoskopi indirek menggunakan video smartphone, manipulasi yang dilakukan lebih minimal karena visualisasi sudah diproyeksikan kamera ke dalam smartphone sehingga tidak terlalu merangsang pasien. Manipulasi pada laringoskopi indirek kaca laring disebabkan oleh pengaturan cahaya lampu pada kepala pemeriksa untuk diproyeksikan pada kaca laring harus berada dalam posisi yang tepat sehingga dapat menghasilkan visualisasi laring yang paling jelas, sedangkan pada laringoskopi indirek video smartphone proyeksi cahaya lampu berada tepat pada ujung video sehingga untuk pengaturan posisi tidak terlalu memengaruhi visualisasi laring.

Keterbatasan penelitian ini terdapat pada subjek penelitian yang dibedakan menjadi 2 kelompok dengan homogenisasi subjek menggunakan kriteria inklusi dan eksklusi. Hal ini dapat memengaruhi hasil penelitian karena seharusnya tiap-tiap subjek pada penelitian ini mendapatkan 2 perlakuan untuk mendapatkan hasil perbandingan yang lebih akurat. Pembagian dua kelompok pada subjek penelitian ini disebabkan oleh masalah etik penelitian yang menentang 1 subjek penelitian dilakukan 2 perlakuan yang berbeda.

\section{Simpulan}

Laringoskopi indirek video smartphone menghasilkan visualisasi yang lebih jelas dan kenyamanan yang lebih baik dibanding dengan laringoskopi indirek kaca laring pada pemeriksaan preoperatif yang dilakukan pada pasien yang akan menjalani pembedahan.

\section{Daftar Pustaka}

1. Budde AO, Desciak M, Reddy V, Falcucci OA, Vaida SJ, Pott LM. The prediction of difficult intubation in obese patients using mirror indirect laryngoscopy: a prospective pilot study. Anaesthesiol Clin 
Pharmacol. 2013;29(2):183-6.

2. Stephen R Collins. Direct and indirect laryngoscopy: equipment and techniques. Respiratory Care. 2014;59(6):850-64.

3. Turkay M, Senturk T, Arslan BY, Yeter H, Sevdi MS, Aydin S, dkk. Indirect laryngoscopic assessment for the diagnosis of difficult intubation in patients undergoing microlaryngeal surgery. Wiener Medizinische Wochensschrift. 2016;166:62-7.

4. Karakus O, Kaya C, Ustun FE, Koksal E, Ustun YB. Predictive value of preoperative tests in estimating difficult intubation in patients who underwent direct laryngoscopy in ear, nose, and throat surgery. Brazilian Anesthesiol. 2015;65(2):85-91.

5. Samsoon GL, Young JR. Difficult tracheal intubation: a retrospective study. Anaesthesia. 1987;42:287-490.

6. Yamamoto K, Tsubokawa T, Shibata
K, Ohmura S, Nitta S, Kobayashi T. Predicting difficult intubation with indirect laryngoscopy. Anesthesiology. 1997;86(2):316-21.

7. Dunklebarger J, Rhee D, Seungwon $\mathrm{K}$, Ferguson B. Video rigid laryngeal endoscopy compared to laryngeal examination: an assessment of patient comfort and clinical visualization. Laryngoscope. 2009;119:269-71.

8. Kendall K. Indirect laryngoscopy: indirect laryngoscopy. Dalam: Kendall K, Leonard RJ, penyunting. Laryngeal evaluation: indirect laryngoscopy to high-speed digital imaging. New York: Thieme Medical Publisher; 2010. hlm. 40-4.

9. Shiga T, Wajima Z, Inoue T, Sakamoto A. Predicting difficultintubation in apparently normal patients: a meta-analysis of bedside screening test performance. Anesthesiology. 2005;103:429-37. 